\title{
Conductive Composites Based on Polyurethane and Nanostructured Conductive Filler of Montmorillonite/Polypyrrole for Electromagnetic Shielding Applications
}

\author{
Patricia Cristine Vargass ${ }^{a}$ Claudia Merlini ${ }^{a, b}$, Sílvia Daniela Araújo da Silva Ramôa ${ }^{a}$, \\ Rafael Arenhart, Guilherme Mariz de Oliveira Barra ${ }^{a} \mathbb{1}^{-}$, Bluma Guenther Soares $^{c}$ \\ ${ }^{a}$ Departamento de Engenharia Mecânica, Universidade Federal de Santa Catarina - UFSC, \\ Florianópolis, SC, Brasil \\ ${ }^{b}$ Departamento de Engenharia, Universidade Federal de Santa Catarina - UFSC, Blumenau, SC, Brasil \\ ${ }^{c}$ Departamento de Engenharia Metalúrgica e de Materiais, Universidade Federal do Rio de Janeiro - \\ UFRJ, Rio de Janeiro, RJ, Brasil
}

Received: January 05, 2018; Revised: April 27, 2018; Accepted: July 09, 2018

\begin{abstract}
In this study, composites based on polyurethane (PU) derived from castor oil and montmorillonite/ polypyrrole doped with dodecylbenzenesulfonic acid (MMt-PPy.DBSA) were developed. In order to investigate the potential use of these materials for electromagnetic shielding applications, the electrical and mechanical properties of PU/MMt-PPy.DBSA composites were determined and compared with composites containing neat PPy.DBSA. The electrical conductivity of PU/MMt-PPy.DBSA composites was found to be higher than those for PU/PPy.DBSA with a similar filler content. Additionally, with a higher conductive additive content, significant increases in the tensile stress $(\sigma)$ and elastic modulus (E) were observed, suggesting that MMt-PPy.DBSA acts as reinforcing agent for the PU matrix. The electromagnetic interference shielding effectiveness (EMI SE) of composites is mainly dependent on the morphology and filler content. The PU/MMt-PPy.DBSA composite containing $25 \mathrm{wt} \%$ of MMt-PPy.DBSA showed a maximum EMI SE of $-21 \mathrm{~dB}$, which is similar to the value required for commercial applications $(-20 \mathrm{~dB})$. The results revealed that PU/MMt-PPy.DBSA composites are promising materials for electromagnetic shielding applications.
\end{abstract}

Keywords: Polypyrrole, montmorillonite, polyurethane derived from castor oil, electromagnetic interference shielding application.

\section{Introduction}

Due to the development of sophisticated and ever smaller electronic devices, electromagnetic interference has become an environmental problem in the modern world ${ }^{1,2}$. Nowadays, electrically conductive polymer composites (ECPCs) are being extensively studied as alternatives to metals, since they offer lower density, easier processing and lower cost. The ECPCs are formed by a conductive additive dispersed in an insulating matrix. Several conductive additives can be used to produce ECPCs, but scientific interest in the use of the intrinsically conducting polymers (ICPs) has been increasing due to their potential in various technological applications. Polypyrrole (PPy) is one of the most widely studied ICPs because of its remarkable and well-known properties, such as high electrical conductivity, chemical and environmental stability, low ionization potential and ease of synthesis ${ }^{3,4}$.

In ECPCs, the electrical conductivity and the electromagnetic interference shielding effectiveness (EMI SE) are dependent on the formation of a conducting network in the insulating polymer matrix. The minimum amount of conductive additive incorporated into the insulating matrix that causes the abrupt increase in electrical conductivity and electromagnetic shielding is known as the percolation threshold. This parameter is dependent on the properties of the conductive filler, such as the surface area and aspect ratio and the properties of the insulating polymer matrix. The percolation threshold is also affected by the interaction between the conductive filler and the polymer matrix, manufacturing process and processing conditions ${ }^{5-7}$.

A major challenge in developing ECPCs filled with ICPs is to reduce the percolation threshold, in order to minimize the processing costs and the reduction in the mechanical properties of the host-insulating polymer. One of the most commonly employed techniques used for this purpose is the preparation of a nanostructured conductive filler through the in situ polymerization of pyrrole in the presence of nanometric materials. In this regard, montmorillonite (MMt) is a promising candidate for obtaining a nanostructured conductive filler due to its layered structure, large surface area, high aspect ratio and chemical and thermal stability. In addition, MMt is a natural material associated with low $\cos ^{8,9}$. Many techniques have been applied to produce nanostructured conductive fillers, but one of the most widely studied consists of inserting PPy into MMt layers through the chemical polymerization of pyrrole in an MMt suspension. This method allows the formation of an exfoliate structure, which results in strong 
interaction between the nanostructured conductive additive and the insulating matrix ${ }^{10-12}$.

Furthermore, the insulating polymer matrix plays an important role in the production of highly electrically conducting polymer composites. Polyurethane (PU) has been widely used to develop ECPCs because of its excellent processability, resistance to solvents and good mechanical properties, which can be adjusted by using different amounts and types of diisocyanates and polyols ${ }^{13}$. Moreover, PU can be synthetized through the polycondensation reaction between diisocyanate and polyol derived from vegetable oils, such as castor oil ${ }^{13,14,15}$, soybean oil and passion fruit oil ${ }^{16}$. Castor oil is of particular interest due to the presence of ricinoleic acid (12-hydroxy-(cis)-9-octadecenoic acid) which represents more than $90 \%$ of the fatty acids in its structure $^{15}$. Moreover, the PU synthesis can be performed at room temperature without the use of solvents or melting.

Several studies have been reported on the synthesis of nanostructured conductive fillers based on MMt-PPy ${ }^{10,11,17,18}$ and its use as a conductive filler for an insulating polymer matrix $^{19-20}$. However, few authors ${ }^{21}$ have reported the preparation of MMt-PPy-filled nanocomposites for application in electromagnetic shielding, or discussed the correlation between the structure and the electromagnetic shielding properties of such nanocomposites.

In this context, the focus of this study was to investigate the structure and properties of polyurethane derived from castor oil and MMt-PPy (PU/MMt-PPy.DBSA) nanocomposites and their potential use for electromagnetic shielding applications.

\section{Experimental}

\subsection{Materials}

Natural sodium bentonite clay (MMt-Na+), (VULGEL $\mathrm{CN} 45$ ), produced by Aliança Latina Indústria e Comércio Ltda, was kindly supplied by the company Ioto International. According to the manufacturer, the MMt displays highpurity, $\mathrm{pH}$ of 5.5 and electrical conductivity of $10^{-6} \mathrm{~S}^{\mathrm{cm}} \mathrm{cm}^{-1}$. Pyrrole (Sigma-Aldrich; $98 \%$ ) was distilled under vacuum and stored in a refrigerator. Iron (III) chloride hexahydrate $\left(\mathrm{FeCl}_{3} \cdot 6 \mathrm{H}_{2} \mathrm{O}\right)$ (analytical grade, Sigma-Aldrich) and surfactant dodecylbenzenesulfonic acid (DBSA) (Sigma-Aldrich) were used without further purification. The company IMPERVEG ${ }^{\circledR}$ Comércio e Prestações de Serviço Ltda supplied the PU derived from castor oil (PU) (IMPERVEG® UG 132 A). The $\mathrm{PU}$ is composed of two components: a polyol derived from castor oil (trifunctional polyester) and a prepolymer, which was synthesized by reacting diphenyl methane diisocyanate (MDI) with polyol, but keeping three percent of the free isocyanate for later reaction.

\subsection{Preparation of montmorillonite/polypyrrole (MMt-PPy)}

Nanostructured conductive filler was prepared according to the method described by Ramoa et al. ${ }^{11}$. Firstly, $1 \mathrm{~g}$ of MMt was dispersed in $100 \mathrm{~mL}$ of aqueous solution containing DBSA and stirred for $2 \mathrm{~h}$ under magnetic stirring at room temperature (molar ratio surfactant/PPy $=1: 5$ ). This suspension was then sonicated in an ultrasonic processor (Sonics VCX 750) with $35 \%$ power $(263 \mathrm{~W}$ ) for $20 \mathrm{~min}$. In the next step, $\mathrm{FeCl}_{3} .6 \mathrm{H}_{2} \mathrm{O}(0.0264 \mathrm{~mol}$ dissolved in 50 $\mathrm{mL}$ of distilled water solution) was added slowly to the $\mathrm{MMt} /$ surfactant suspension under magnetic stirring at room temperature. After $15 \mathrm{~min}$, pyrrole $(0.0115 \mathrm{~mol})$ dispersed in $20 \mathrm{~mL}$ of distilled water (molar ratio $\mathrm{MMt} / \mathrm{PPy}=1: 5$ ) was added dropwise. The polymerization was carried out for 1 $\mathrm{h}$ under magnetic stirring at room temperature. After $24 \mathrm{~h}$, the nanostructured conductive additives (MMt-PPy.DBSA) were filtered, washed with distilled water and dried at $60^{\circ} \mathrm{C}$. The synthesis of neat PPy.DBSA was carried out following the same procedure, but without the presence of MMt.

\subsection{Preparation of PU/MMt-PPy.DBSA composites}

The prepolymer (component A) and the polyol derived from castor oil (component B) were blended in a mass ratio of $1: 2$, respectively. Subsequently, different weight concentrations of MMT-PPy.DBSA were then manually blended into the PU mixture for $5 \mathrm{~min}$. The mixtures were placed in a metallic mold, left for $2 \mathrm{~h}$ at room temperature and then subjected to compression molding at 10.7 MPa for $4 \mathrm{~h}$. After $6 \mathrm{~h}$, the compression stress was released and the composites kept at room temperature in vacuum desiccator for $24 \mathrm{~h}$ to complete the cure. The whole procedure was performed at room temperature $\left(23 \pm 2^{\circ} \mathrm{C}\right)$. PU/PPy.DBSA composites were prepared using the same procedure.

\subsection{Characterizations}

The electrical conductivity of the conductive fillers and high-conductivity composites was measured using a Keithley 6220 current source to apply the current and a Keithley Model 6517A(Oklahoma, U.S.A.) electrometer to measure the potential difference. The PU and low-conductivity composite measurements were performed using a Keithley 6517A electrometer connected to a Keithley 8009 test fixture.

Elemental analysis (carbon, hydrogen and nitrogen) was performed with a Perkin-Elmer CHN 2400 analyzer, at $95^{\circ} \mathrm{C}$ using oxygen $(99.995 \%$ ). The PPy.DBSA content of the nanostructure conductive additive was calculated, based on $\mathrm{CHN}$ results, from the proportion of nitrogen in the MMt-PPy.DBSA and the neat PPy.DBSA, according to the methodology reported by Merlini et al., $2017^{13}$. 
The specific surface areas (SSAs) of the conductive fillers were determined by the BET nitrogen adsorption method (Quantachrome Instruments - Autosorb-1). Physisorption tests were performed to determine the area by BET following the ASTM D 6556. The samples were previously dried at $70^{\circ} \mathrm{C}$ under vacuum $\left(10^{-7}\right.$ torr $)$ and then the nitrogen gas adsorption was measured at $77 \mathrm{~K}$ in relative pressure values in the range from 0 to 1.0 .

Transmission electron microscopy (TEM) was carried out on a Jeol JEM-1100 microscope operating at an accelerating voltage of $100 \mathrm{kV}$. The composites were cut into ultrathin slices ( $\sim 80 \mathrm{~nm}$ thick) using a diamond knife in an ultramicrotome (RMC Boeckeler) and deposited on a 200-mesh copper grid for subsequent observations.

The X-ray diffraction (XRD) patterns of MMt, MMt-PPy. DBSA and composites with 5 and $20 \mathrm{wt} \%$ of MMt-PPy.DBSA were obtained on an X'pert (Philips) X-ray diffractometer with $\mathrm{CuK} \alpha$ radiation $(\lambda=0,154 \mathrm{~nm})$ at $40 \mathrm{kV}$ and $30 \mathrm{~mA}$. The samples were evaluated from $2^{\circ}$ to $10^{\circ}\left(2 \theta^{\circ}\right)$ with $0.05^{\circ}$ steps and a $1 \mathrm{~s}$ time step.

Thermogravimetric analysis (TGA) was carried out using a STA 449 F1 JupiterVR (Netzsch) thermogravimetric analyzer. The analyses were performed at $10^{\circ} \mathrm{C} \mathrm{min}^{-1}$ from $35^{\circ} \mathrm{C}$ to $950^{\circ} \mathrm{C}$ under an air flux of $50 \mathrm{~mL} \mathrm{~min}{ }^{-1}$.

The tensile properties of the neat $\mathrm{PU}$ and the composites were determined using a dynamic mechanical analyzer (DMA Q-800, TA Scientific) in the tensile mode on rectangular specimens with a $5 \mathrm{~mm}$ width, $35 \mathrm{~mm}$ length and $0.2 \mathrm{~mm}$ thickness. The mechanical tests were performed at a test speed of $3 \mathrm{~mm} \cdot \mathrm{min}^{-1}$ in the range of 0 to $18 \mathrm{~N}$.

The electromagnetic interference shielding effectiveness (EMI SE) of neat PU and the composites was measured using an Agilent Technology PNA series network analyzer (N5230C Agilent PNA-L) and a standard rectangular waveguide in the $\mathrm{X}$-band frequency range $(8.2-12.4 \mathrm{GHz})$. EMI SE measurements were performed on rectangular specimens with $10 \mathrm{~mm}$ width, $23 \mathrm{~mm}$ length and 2.0, 5.0 or $8.0 \mathrm{~mm}$ thickness.

\section{Results and Discussion}

Figure 1 shows the curves of the electrical conductivity of PU/MMT-PPy.DBSA and PU/PPy.DBSA as a function of the filler content and type, and TEM micrographs of composites. On increasing the MMt-PPy.DBSA concentration, the electrical
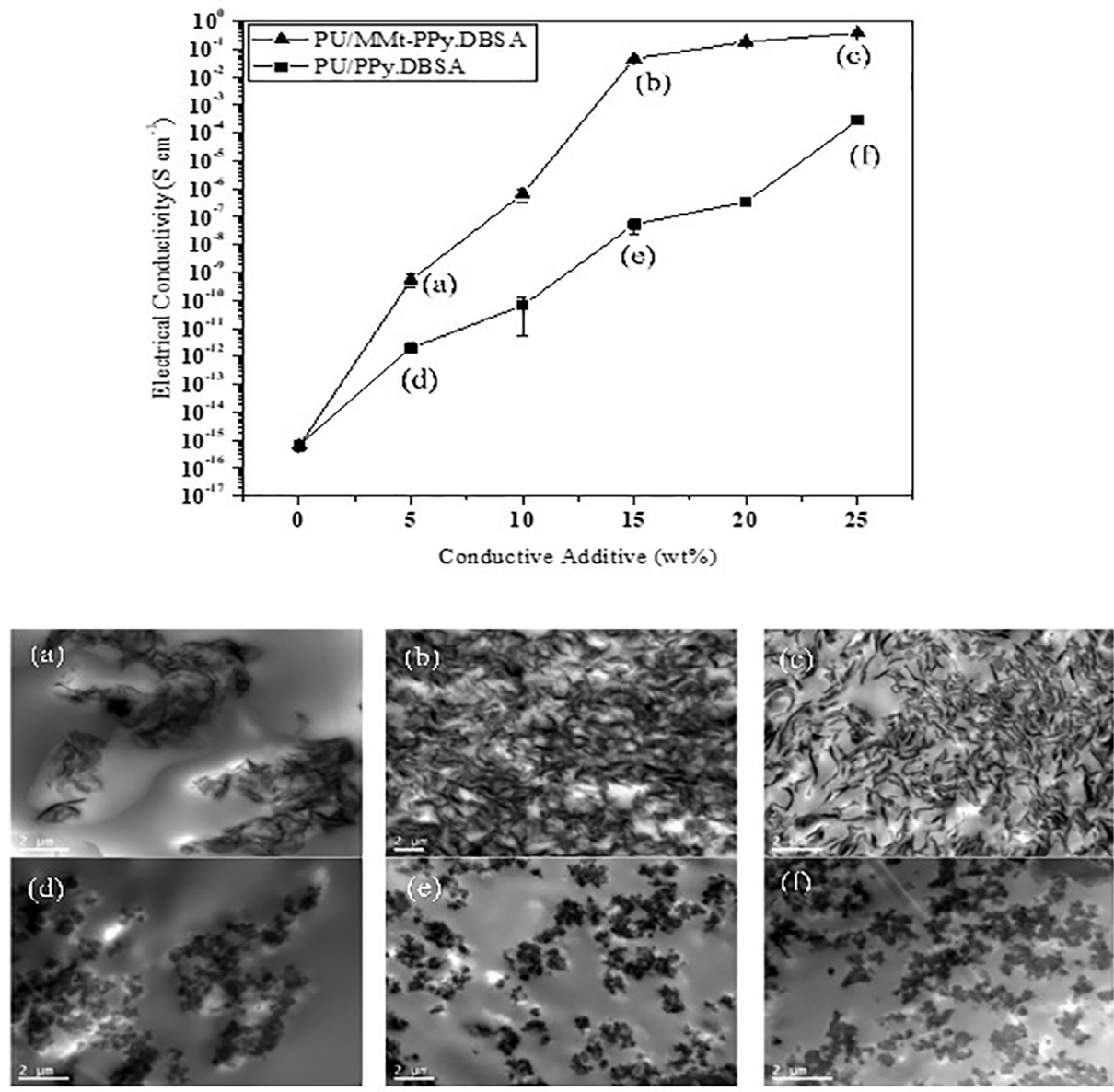

Figure 1. The effect of conductive additive content on the electrical conductivity of the composites. TEM micrographs of PU/MMt-PPy.DBSA (a, b and c) and PU/PPy.DBSA (d, e and f), with 5, 15 and $25 \mathrm{wt} \%$ of conductive additive, respectively. 
conductivity of the PU/MMt-PPy.DBSA composites increased due to the formation of a conducting polymer network in the insulating polymer matrix. Analogous behavior was observed for the PU/PPy.DBSA composites; however, this polymer system presented lower electrical conductivity than that found for the PU/MMt-PPy.DBSA nanocomposite. For 25 wt $\%$ of conductive filler, the electrical conductivity of PU/ MMt-PPy.DBSA was 3.79x $10^{-1} \mathrm{~S} \mathrm{~cm}^{-1}$, while PU/PPy.DBSA reached a value of $2.77 \times 10^{-4} \mathrm{~S} \mathrm{~cm}^{-1}$, these values being 15 and 12 orders of magnitude higher, respectively, than the neat PU $\left(6.63 \times 10^{-16} \mathrm{~S} \mathrm{~cm}^{-1}\right)$. These results are consistent with the TEM micrographs of composites with 5, 15 and $25 \mathrm{wt} \%$ of MMt-PPy.DBSA and PPy.DBSA, (Figure 1). In these images it can be observed that the MMt-PPy.DBSA is well-dispersed while PPy.DBSA agglomerates are observed in the PU matrix.

Moreover, the MMt-PPy.DBSA is comprised of a layered structure (MMt layers coated with PPy), intercalated and

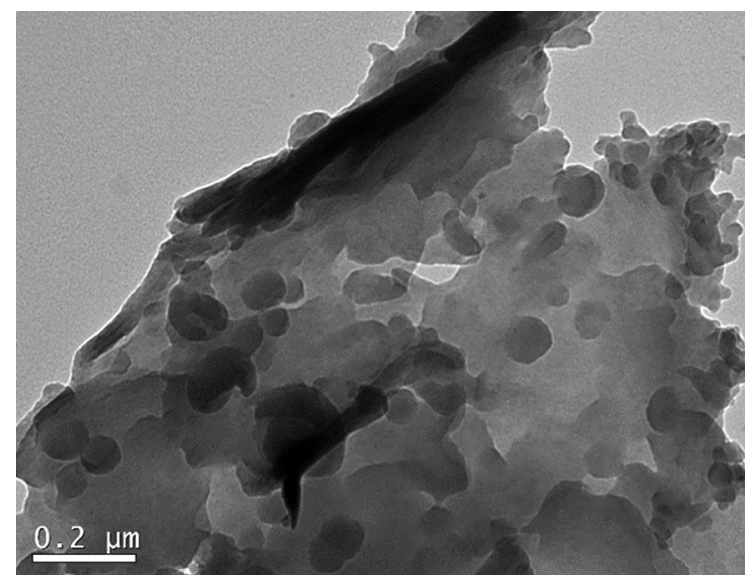

Figure 2. TEM micrograph of nanostructured conductive filler of MMt-PPy.DBSA. partially exfoliated, as showed in the Figure 2, which result in a large surface area $\left(3.52 \mathrm{~m}^{2} \mathrm{~g}^{-1}\right)$ that enable the formation of a conductive network in the PU matrix at lower filler content than in the case of PU/PPy.DBSA (surface area of $\left.2.06 \mathrm{~m}^{2} \mathrm{~g}^{-1}\right)$. Similar results have been reported by Ramoa et al. ${ }^{10}$, for thermoplastic polyurethane/montmorillonitepolypyrrole nanocomposites.

The percolation thresholds of PU/MMt-PPy.DBSA and PU/PPy-DBSA were calculated according to the model proposed by Kirkpatrick ${ }^{22}$ (Eq. 1) in which $\sigma$ is the conductivity, $\sigma_{c}$ a constant, $t$ a critical exponent, $f$ the fraction of the conductive filler and $f_{p}$ the fraction at the percolation threshold, expressed as a weight fraction:

$$
\sigma=\sigma_{c}\left(f-f_{p}\right)^{t}
$$

The values of percolation threshold $\left(f_{\mathrm{p}}\right)$, were determined through the plot of $\log \sigma$ versus $\log \left(f-f_{\mathrm{p}}\right)$, of PU/MMt.PPy.DBSA and PU/PPy.DBSA, resulted to be 1 wt $\%$ and 5 wt $\%$, respectively. The percolation threshold of PU/MMt-PPy.DBSA is significantly lower than those reported by Ramoa et al. ${ }^{10}$ for nanocomposites based on thermoplastic polyurethane (TPU) and MMt-PPy.DBSA This difference can be mainly attributed to the distribution of the filler in the matrix and better interaction between the thermoset PU and MMt-PPy.DBSA. Moreover, the use of high process temperature $\left(170^{\circ} \mathrm{C}\right)^{18}$ can compromise the electrical properties of the composites. In our work, the composites was prepared at room temperature that also can contribute to the superior electrical properties.

Figure 3 illustrates the TEM micrographs with a higher magnification for both the polymer systems. The TEM images reveal an intercalated structure for neat MMt-PPy.DBSA
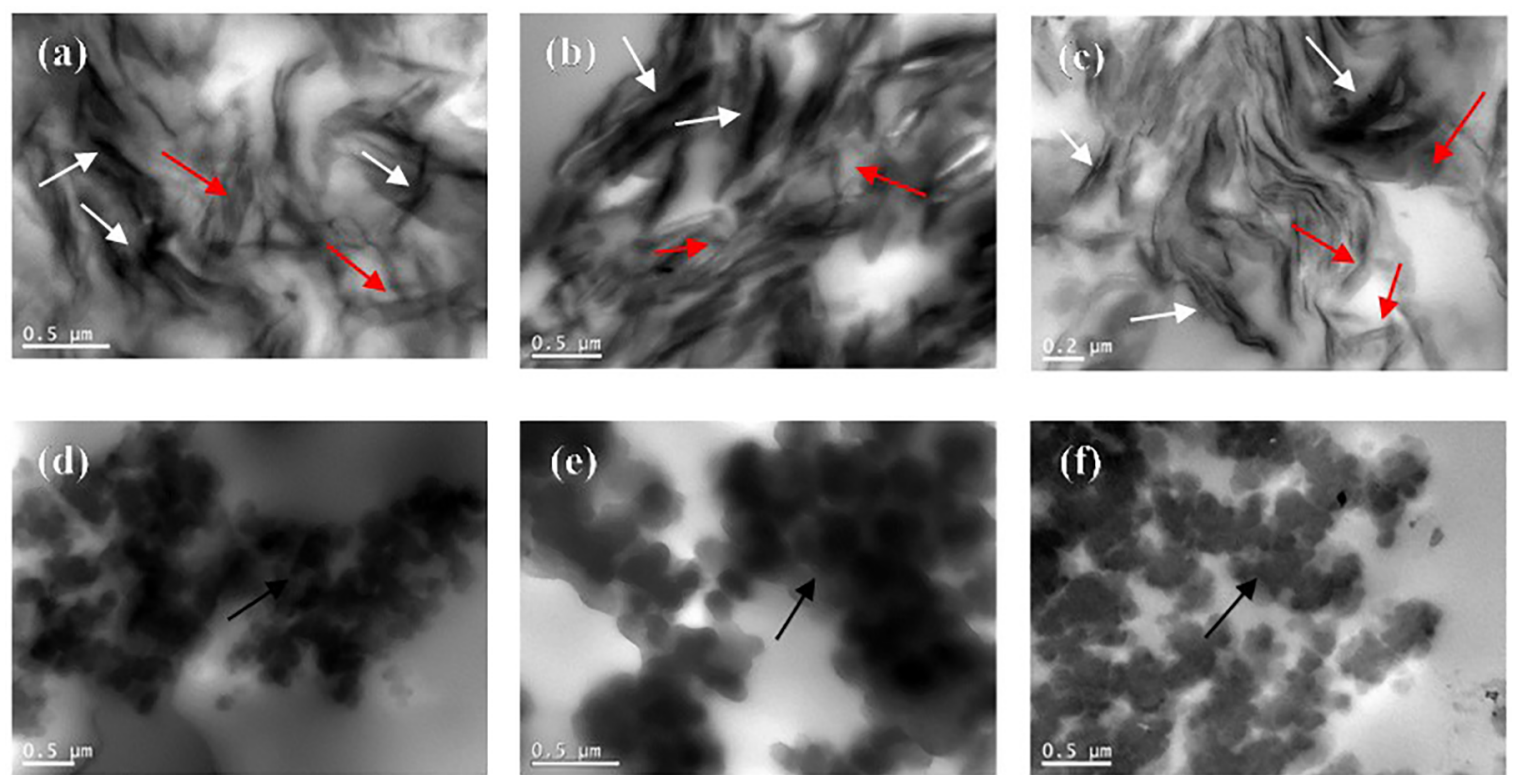

Figure 3. TEM micrographs of PU/MMt-PPy.DBSA composites (a, b and c) and PU/PPy.DBSA composites (d, e and f), with 5, 15 and $25 \mathrm{wt} \%$ of filler. 
(white arrow). This behavior can be attributed to the fact that during the synthesis, the monomer is able to penetrate between the MMT layers, and the the PPy chains allow to increase the distance between the MMt sheets. When the MMt-PPy.DBSA is introduced into PU matrix, is possible to note that composites exhibits an intercalated and partial exfoliated (red arrow) morphology (Figure 3(a, b and c)). On the other hand, the PU/PPy.DBSA composites with different filler amounts (Figure 3 (d, e and f)) exhibited agglomerated particles of PPy.DBSA (black arrow) which are poorly distributed in the PU matrix. This microstructure explains the lower electrical conductivity and higher percolation threshold observed for the PU/PPy.DBSA when compared to the PU/MMt-PPy.DBSA.

The intercalated and partially exfoliated structure of MMt-PPy.DBSA in the PU matrix was confirmed by the XRD curves (Figure 4). The 001 reflection of the neat MMt (Figure 4(a)) and its $d$-value were $2 \theta=8.57^{\circ}$ and $1.03 \mathrm{~nm}$, respectively. On the other hand, MMt-PPy.DBSA(Figure 4(b)) did not show this diffraction peak (001). According to Ray and Okamoto $^{23}$, this behavior indicates an intercalated/ partially exfoliated structure formation. The same behavior was observed for the PU/MMt-PPy.DBSA composites, as shown in Figure 4(c) and 4(d), suggesting an intercalation/ partial exfoliation of MMt-PPy.DBSA in the PU matrix.

The addition of MMt-PPy.DBSA and PPy.DBSA changes the mechanical properties of $\mathrm{PU}$, as can be seen in the representative stress versus strain curves (Figure 5). The tensile properties of the neat $\mathrm{PU}$ and composites are shown in Table 1. When the PU is subjected to tension, it displays a ductile and flexible behavior, with a tensile stress of 1.4 MPa and elastic modulus of 3.3 MPa, respectively. It can be noted that when the MMt-PPy.DBSA content is increased, the tensile stress values and elastic modulus increase and the composites become stiffer, indicating that the nanostructured

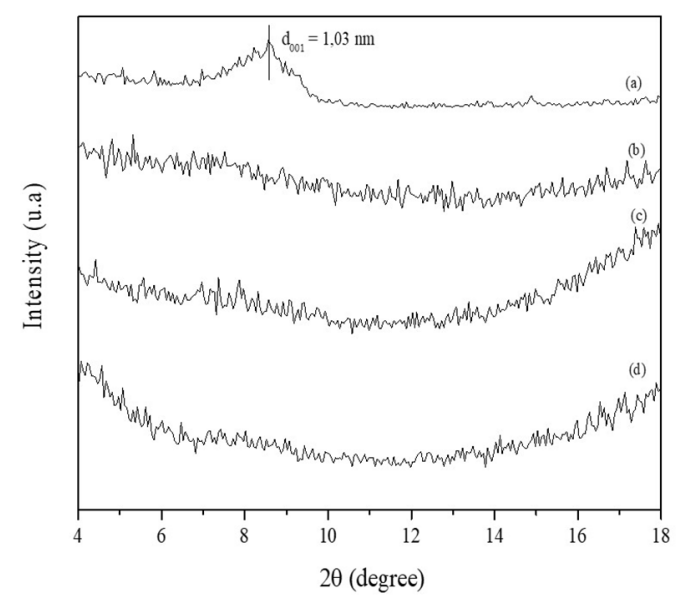

Figure 4. XRD diagrams: (a) neat MMt, (b) MMt-PPy.DBSA and PU/MMt-PPy.DBSA with nanostructured conductive additive content of (c) $5 \mathrm{wt} \%$ and (d) $20 \mathrm{wt} \%$.
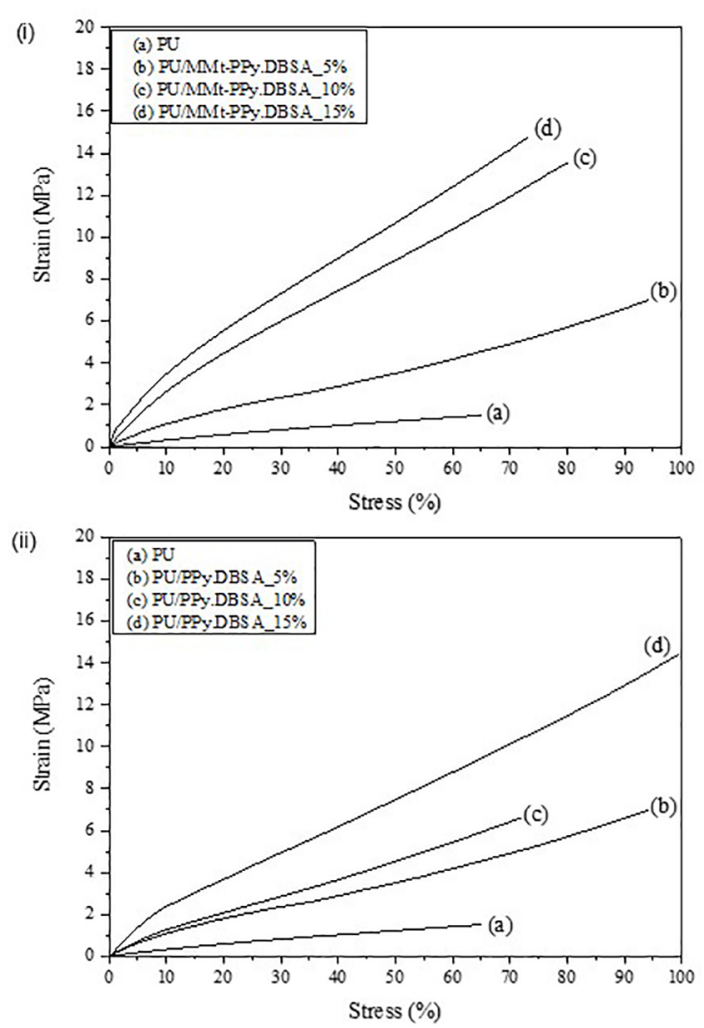

Figure 5. Representative stress versus strain curves: (i) neat PU and PU/MMt-PPy.DBSA with 5, 10 and $15 \mathrm{wt} \%$ of MMt-PPy. DBSA and (ii) neat PU and PU/PPy.DBSA with 5, 10 and $15 \mathrm{wt}$ $\%$ of PPy.DBSA.

conductive additive is acting as a reinforcement agent. Similar behavior can be observed for the PU/PPy.DBSA composites, where the tensile stress and elastic modulus also increase with increasing PPy.DBSA content, but the variation is not as significant as that observed for the PU/MMt-PPy.DBSA composites. The reinforcement effect of PPy.DBSA may be caused by chemical bonding between the $\mathrm{N}-\mathrm{H}$ in the pyrrole ring (amine groups) and polyurethane $(\mathrm{C}=\mathrm{O}$ groups $)$, that enhance the adhesion in the interface. The better properties of the PU/MMt-PPy.DBSA when compared to the PU/ PPy. DBSA may be related to the better dispersion, higher aspect ratio and larger surface area of the nanostructured conductive additive, which result in a more effective interaction between the phases. Furthermore, the clay layer dispersion in the PU matrix leads to improvements in the tensile strength and elasticity modulus ${ }^{19}$. It is important to highlight that mixtures containing 20 and $25 \mathrm{wt} \%$ of MMt-PPy.DBSA and PPy. DBSA did not break during the test, which indicates that the force needed to break the samples is higher than $18 \mathrm{~N}$ (maximum force that can be applied by the equipment). The improvement in the mechanical properties of both polymer systems is a very interesting result since the addition of a 
Table 1. Tensile properties of neat PU, composites and blends with different conductive additives content

\begin{tabular}{|c|c|c|c|c|}
\hline Sample & $\sigma(\mathrm{MPa})$ & $\varepsilon(\%)$ & E (MPa) & Fracture Toughness \\
\hline PU & $1.4 \pm 0.1$ & $68.0 \pm 8.9$ & $3.3 \pm 0.1$ & $49.5 \pm 4.3$ \\
\hline $\begin{array}{l}\text { PU/MMt-PPy. } \\
\text { DBSA_5\% }\end{array}$ & $7.6 \pm 0.5$ & $99.5 \pm 0.3$ & $13.9 \pm 0.6$ & $376.8 \pm 25.4$ \\
\hline $\begin{array}{l}\text { PU/MMt-PPy. } \\
\text { DBSA_10\% }\end{array}$ & $14.5 \pm 2.1$ & $89.9 \pm 10.0$ & $38.2 \pm 5.2$ & $376.8 \pm 25.4$ \\
\hline $\begin{array}{l}\text { PU/MMt-PPy. } \\
\text { DBSA_15\% }\end{array}$ & $15.1 \pm 1.5$ & $79.2 \pm 12.6$ & $66.1 \pm 3.7$ & $515.1 \pm 37.6$ \\
\hline $\begin{array}{l}\text { PU/MMt-PPy. } \\
\text { DBSA_20\%* }\end{array}$ & - & - & - & - \\
\hline $\begin{array}{l}\text { PU/MMt-PPy. } \\
\text { DBSA_25\%* }\end{array}$ & - & - & - & - \\
\hline PU/PPy.DBSA_5\% & $7.2 \pm 0.2$ & $87.6 \pm 5.7$ & $13.6 \pm 0.8$ & $316.5 \pm 12.2$ \\
\hline PU/PPy.DBSA_10\% & $8.0 \pm 1.2$ & $78.6 \pm 9.5$ & $17.9 \pm 2.3$ & $259.8 \pm 31.8$ \\
\hline PU/PPy.DBSA_15\% & $12.8 \pm 1.8$ & $99.7 \pm 0.3$ & $32.5 \pm 5.2$ & $689.8 \pm 38.9$ \\
\hline PU/PPy.DBSA_20\%* & - & - & - & - \\
\hline PU/PPy.DBSA_25\%* & - & - & - & - \\
\hline
\end{tabular}

*Samples not broken.

conducting polymer to a polymeric matrix generally leads to a significant reduction in the mechanical properties ${ }^{10}$.

Figure 6 shown the TG curves of neat MMt, PPy.DBSA and MMt-PPy.DBSA. The MMt present two steps of weight at $100^{\circ} \mathrm{C}$ and $600^{\circ} \mathrm{C}$. The first event observed for the MMt correspond to the elimination of water and the second is related to aluminum silicate dehydroxylation ${ }^{11}$. PPy exhibits a continuous weight loss starting at $220^{\circ} \mathrm{C}$ that is assigned to the polymer chain degradation ${ }^{16}$. The TG curve for MMt-PPy. DBSA is similar to that observed for the neat PPy; however, the nanoestrucuted conductive additive has enhanced thermal stability, since the degradation onset temperatures was higher than for the neat PPy. This behavior can be associated to the barrier effect of the clay layer and formation of an intercalated/partially exfoliated structure ${ }^{11}$. The amount of residues generated in the TGA was used to estimate the PPy and MMt content in the nanostructured conductive filler that was of $88 \mathrm{wt} \%$ and $12 \mathrm{wt} \%$, respectively.

Figure 7 illustrates the weight loss curves obtained by TGA and the first derivative (DTG) for PU, PU/MMt-PPy. DBSA and PU/PPy.DBSA. The neat PU presents 4 steps of weight loss: i) the first at $\mathrm{T}_{\text {max }}$ at $317^{\circ} \mathrm{C}$ is related at breakage of urethane bonds; ii) the second at $\mathrm{T}_{\text {max }}$ at $389^{\circ} \mathrm{C}$ is related to breaking esters bonds which are present in the prepolymer; iii) both stages at $\mathrm{T}_{\text {max }}$ at $458^{\circ} \mathrm{C}$ and $\mathrm{T}_{\text {max }}$ at $590^{\circ} \mathrm{C}$ correspond to the degradation of polyol ${ }^{16}$. It is possible to note that the composites display a similar behavior that those to neat PU. However, in the composites the initial temperatures of degradation was shifted to lower temperatures, due to the presence of PPy. The amount of residue at $900^{\circ} \mathrm{C}$ for the PU/ MMt-PPy.DBSA composites ranged from 2.9 to $4.8 \mathrm{wt} \%$ due to the presence of MMT that display thermal stability at this temperature.

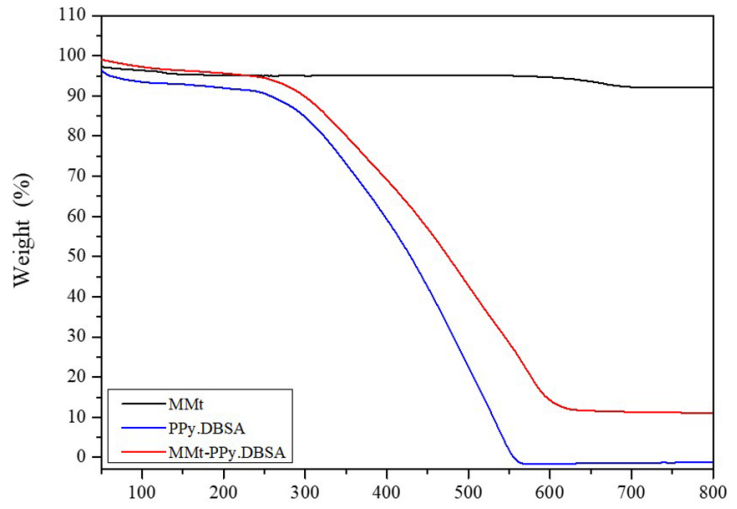

Figure 6. TG curves for MMt, PPy.DBSA and MMt-PPy.DBSA.

The electromagnetic interference shielding effectiveness (EMI SE) of a material can be defined as the ratio between the incident (I) and transmitted (T) power, and is calculated by Eq. $2^{13}$ :

$$
\mathrm{EMI} \mathrm{SE}=10 \log \mathrm{I} / \mathrm{T}
$$

Figure 8 shows the plot of EMI SE as a function of the type and content of the conductive filler for samples with a thickness of $2 \mathrm{~mm}$. With increasing filler content the EMI SE values for PU/MMt-PPy.DBSA and PU/PPy.DBSA increased, due to the formation of a conductive network that induces higher electrical conductivity and interaction of the additives with electromagnetic radiation. In general, the PU/ MMt-PPy.DBSA composites showed higher EMI SE values when compared to the PU/PPy.DBSA. This behavior may be associated with the higher aspect ratio and better distribution of MMt-PPy.DBSA in the PU matrix when compared to PPy. DBSA $^{4}$. The PU/MMt-PPy.DBSA composite with 25 wt \% 
(a)

(b)
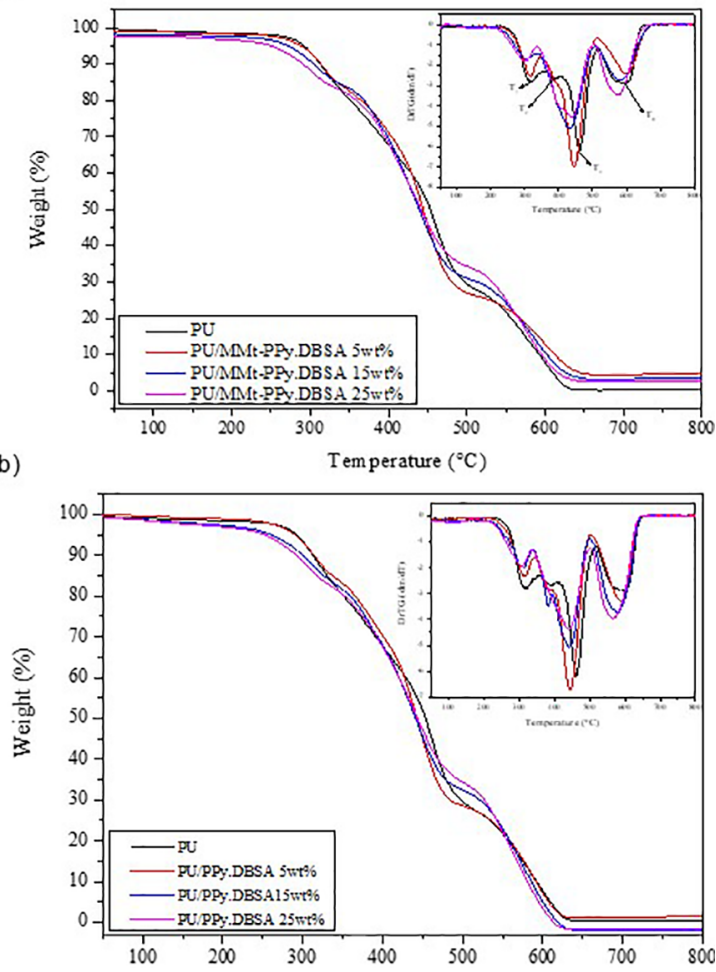

Figure 7. TG and DTG curves for: (a) PU/MMt-PPy.DBSA and (b) PU/PPy.DBSA composites.

of additive displays an average EMI SE of $-20.9 \mathrm{~dB}$ in the frequency range of 8.2 to $12.4 \mathrm{GHz}$, which corresponds to $99.1 \%$ of radiation attenuation. On the other hand, for the same PPy.DBSA content, the maximum EMI SE value was $-17.2 \mathrm{~dB}(97.8 \%$ of radiation attenuation). It is interesting to note that the composites produced in this work manifest EMI SE significantly higher than other composites containing PPy.DBSA, MMt-PPy.DBSA or PAni.DBSA. Thermoplastic polyurethane-filled montmorillonite-polypyrrole (TPU/MMtPPy.DBSA) and with neat PPy.DBSA display total EMI SE of $-16.6 \mathrm{~dB}$ and $-7.2 \mathrm{~dB}$, respectively, for nanocomposites containing $30 \mathrm{wt} \%$ of Mt-PPy.DBSA ${ }^{20}$. For SBS/PAni. DBSA blends the EMI SE of blend containing $30 \mathrm{wt} \%$ of PAni.DBSA is round $-14 \mathrm{~dB}^{24}$.

The EMI SE values for PU/MMt-PPy.DBSA and PU/ PPy.DBSA are not influenced by the frequency, except for the polymer systems with 20 and 25 wt $\%$ of conductive filler. These results can be attributed to the formation of a conducting network and the higher electrical conductivity values of the composites with MMt-PPy.DBSA contents of 20 and 25 wt $\%{ }^{1}$.

Figure 9 shows the EMI SE as a function of the MMtPPy.DBSA and PPy.DBSA contents of the composites with $2 \mathrm{~mm}$ of thickness for frequencies of 8.2, 10 and $12.4 \mathrm{GHz}$. It can be noted that at all selected frequencies, the EMI SE
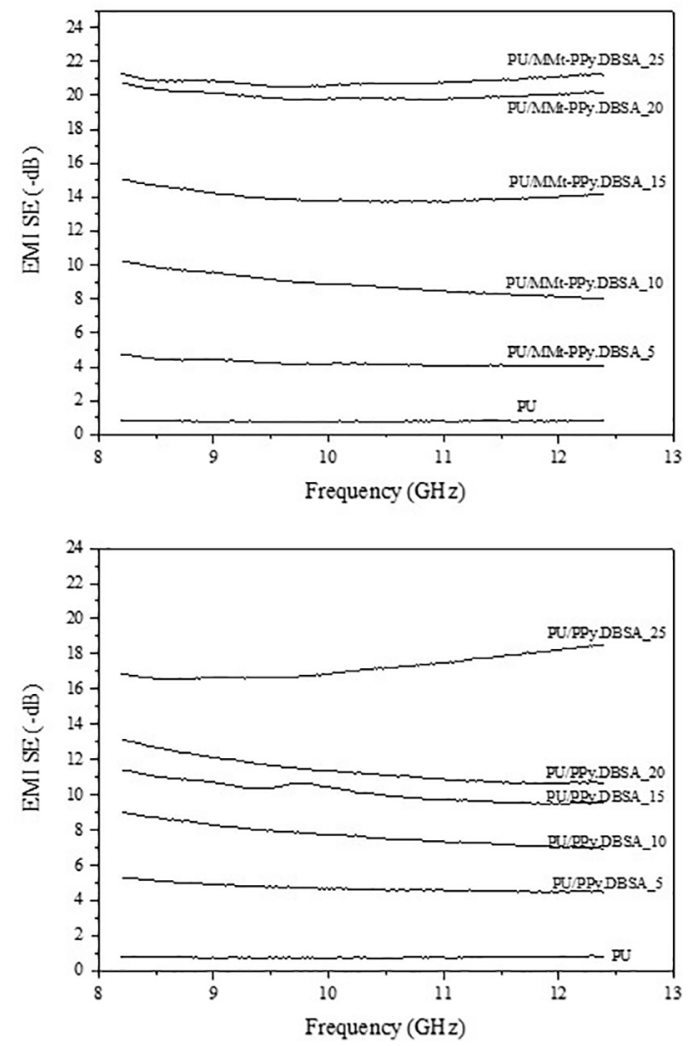

Figure 8. EMI SE of neat PU, PU/MMt-PPy.DBSA and PU/PPy. DBSA composites with different filler contents

of the composites increases up to $20 \mathrm{wt} \%$ of MMt-PPy. DBSA and then remains practically constant. The EMI SE of the PU/PPy.DBSA also increases with increasing PPy. DBSA content, but the most significant change occurs at a content of $20 \mathrm{wt} \%$ PPy.DBSA.

The linear regression model for the EMI SE as a function of the conductive filler content for each frequency is also shown in the Figure 9. This model can be used to predict the MMt-PPy.DBSA or PPy.DBSA content (X) which will provide a desired EMI SE value, at a specific frequency, or to estimate the EMI SE for a mixture with a specific MMt-PPy.DBSA or PPy.DBSA content ${ }^{13}$. For example, PU/ MMt-PPy.DBSA with 34.16 wt \% of MMt-PPy.DBSA has an EMI SE value of $-30 \mathrm{~dB}$ at $10 \mathrm{GHz}$. On the other hand, the same EMI SE value can be achieved with the addition of 50.3 wt \% of PPy.DBSA to the PU matrix.

In order to evaluate the reflection and absorption contributions to the total EMI SE of the composites, the transmitted ( $\mathrm{T}$ ), reflected (R) and absorption (A) powers were calculated using the complex scattering parameters that represent the reflection $\mathrm{S}_{11}\left(\mathrm{~S}_{22}\right)$ and transmission $\mathrm{S}_{12}$ 

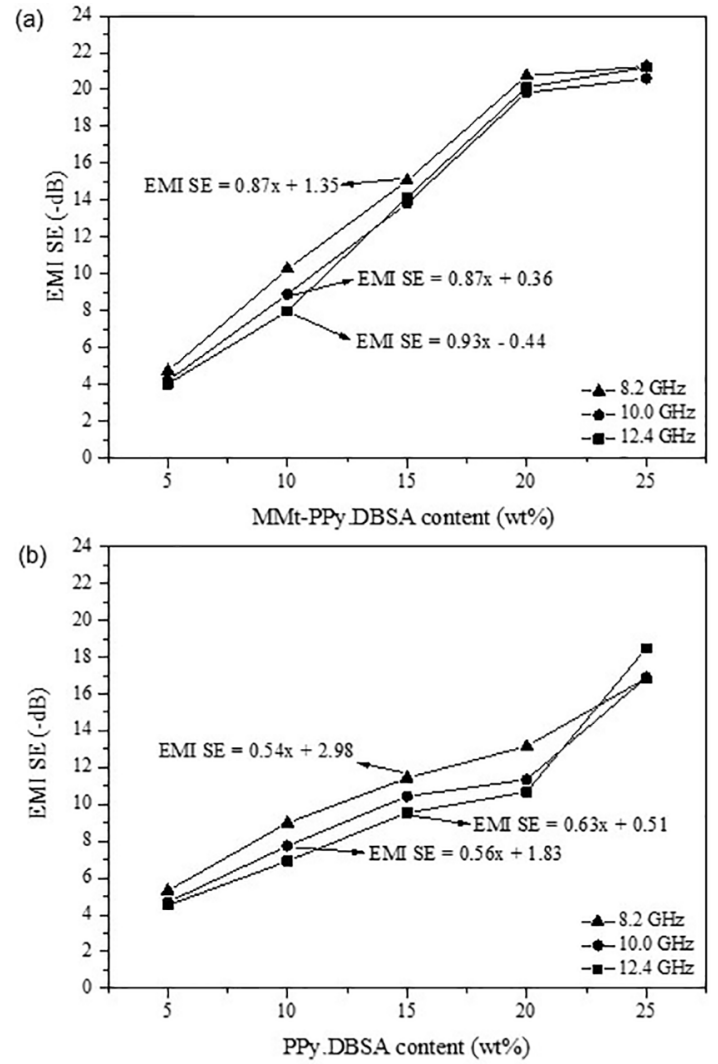

Figure 9. EMI SE as a function of (a) MMt-PPy.DBSA and (b) PPy.DBSA content.

$\left(\mathrm{S}_{21}\right)$ coefficients (collected directly by the instrument used to measure the EMI SE of the samples) and Equations (3), (4) and (5), respectively, according reported by Merlini et al., $2017^{6}$, Ramoa et al., $2018^{20}$ and Merlini et al., 2017 ${ }^{13}$.

$$
\begin{gathered}
\mathrm{T}=\left|\mathrm{E}_{\mathrm{T}} / \mathrm{E}_{\mathrm{I}}\right|^{2}=\left|\mathrm{S}_{12}\right|^{2}\left(=\left|\mathrm{S}_{21}\right|^{2}\right) \\
\mathrm{R}=\left|\mathrm{E}_{\mathrm{R}} / \mathrm{E}_{\mathrm{I}}\right|^{2}=\left|\mathrm{S}_{11}\right|^{2}\left(=\left|\mathrm{S}_{22}\right|^{2}\right) \\
\mathrm{A}=1-\mathrm{R}-\mathrm{T}
\end{gathered}
$$

The reflection $\left(\mathrm{SE}_{\mathrm{R}}\right)$ and absorption $\left(\mathrm{SE}_{\mathrm{A}}\right)$ contributions were calculated using the incident (I), transmitted $(\mathrm{T})$ and reflected (R) powers and Equations (6) and (7), respectively:

$$
\begin{gathered}
\mathrm{SE}_{\mathrm{R}}=10 \log \mathrm{I} / \mathrm{I}-\mathrm{R} \\
\mathrm{SE}_{\mathrm{A}}=10 \log \mathrm{I}-\mathrm{R} / \mathrm{T}
\end{gathered}
$$

(a)

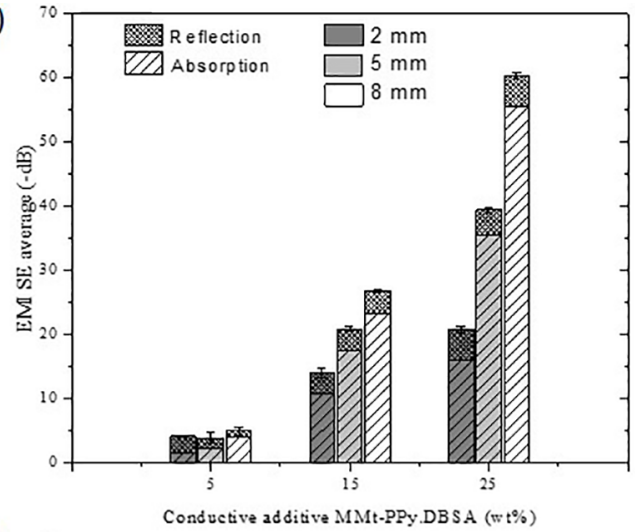

(b)

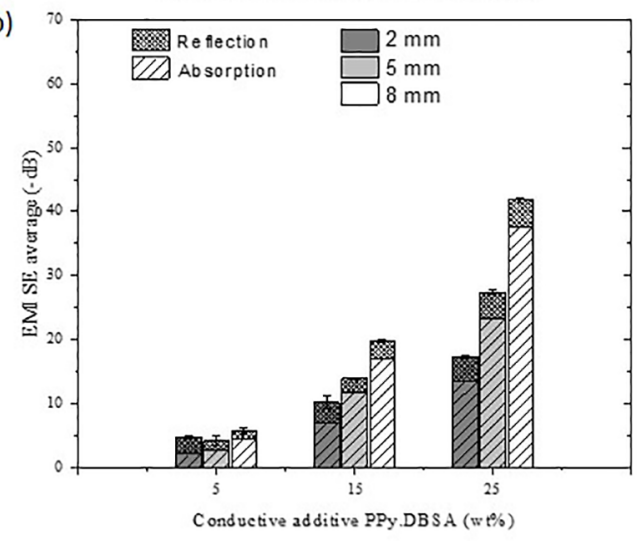

Figure 10. Influence of absorption and reflection mechanisms on the EMI SE of (a) PU/MMt-PPy.DBSA and (b) PU/PPy.DBSA composites with different filler contents and thicknesses.

Figure 10 shows the reflection and absorption contributions to the total EMI SE for the PU/MMt-PPy.DBSA (Fig. 10a) and PU/PPy.DBSA composites (Fig. 10b) with different filler contents and thicknesses. The results are reported as average values in the frequency range of 8.2 to $12.4 \mathrm{GHz}$. It is important to highlight that the total EMI SE increases significantly with increasing of filler content and sample thickness for both composites PU/MMt-PPy.DBSA and PU/PPy.DBSA. However, PU/MMt-PPy.DBSA composites display higher EMI SE values than those found for PU/PPy. DBSA due to the high aspect ratio of MMt-PPy.DBSA, which facilitates the formation of a conductive network, contributing with the electromagnetic radiation interaction. Besides that, the shielding by absorption increases with increasing conductive filler and thickness, while the shielding by reflection remains practically constant. The $\mathrm{SE}_{\mathrm{A}}$ becomes the main EMI shielding mechanism for both composites due to the conducting pathway formation into PU matrix that facilitates the charge carrier movement and better electromagnetic radiation interactions ${ }^{20}$. 


\section{Conclusions}

PU/MMt-PPy.DBSA composites were successfully obtained by the compression molding technique. The results observed in this study revealed that PU/MMt-PPy.DBSA composites show superior tensile properties, electrical conductivity and EMI SE compared with the composites prepared with neat PPy. The addition of MMt-PPy.DBSA to the PU matrix increases its electrical conductivity by 15 orders of magnitude, reaching similar values to the neat MMt-PPy. This behavior was assigned to the lamellar morphology of the nanostructured conductive additive, which allows the formation of conductive pathways with a low conductive additive content, due to its high aspect ratio. Moreover, the composites showed an intercalated/partially exfoliated structure, with a stronger interaction between the nanostructured conductive additive and the matrix. The tensile stress $(\sigma)$ and Young's modulus (E) increased with the additive content, indicating that both additives acted as a reinforcing agent. PU/MMt-PPy.DBSA composites also showed electromagnetic radiation attenuation and the response magnitude was influenced by the MMt-PPy.DBSA weight fraction and sample thickness. The materials developed in this study demonstrated adequate properties for used as effective and lightweight materials for electromagnetic interference shielding.

\section{Acknowledgements}

The authors gratefully acknowledge the financial support of the Brazilian governmental agencies Conselho Nacional de Desenvolvimento Científico e Tecnológico (CNPq), Coordenação de Aperfeiçoamento de Pessoal de Ensino Superior (CAPES) and Fundação de Amparo à Pesquisa e Inovação do Estado de Santa Catarina (FAPESC). We also thank the Central Electronic Microscopy Laboratory, Santa Catarina Federal University (LCME-UFSC).

\section{References}

1. Ramôa SDAS, Barra GMO, Oliveira RBV, Oliveira MG, Cossa $\mathrm{M}$, Soares BG. Electrical, rheological and electromagnetic interference shielding properties of thermoplastic polyurethane/ carbon nanotube composites. Polymer International. 2013;62(10):1477-1484.

2. Wang Y, Jing X. Intrinsically conducting polymers for electromagnetic interference shielding. Polymers Advanced Technologies. 2005;16(4):344-351.

3. Kim BH, Hong SH, Joo J, Park IW, Epstein AJ, Kim JW, et al. Electron spin resonance signal of nanocomposite of conducting polypyrrole with inorganic clay. Journal of Applied Physics. 2004;95(5):2697-2701.

4. Letaïef S, Aranda P, Ruiz-Hitzky E. Influence of iron in the formation of conductive polypyrrole-clay nanocomposites. Applied Clay Science. 2005;28(1-4):183-198.
5. Li J, Kim JK. Percolation threshold of conducting polymer composites containing 3D randomly distributed graphite nanoplatelets. Composites Science and Technology. 2007;67(10):2114-2120.

6. Merlini C, Pegoretti A, Vargas PC, Cunha TF, Ramôa SDAS, Soares BG, et al. Electromagnetic interference shielding effectiveness of composites based on polyurethane derived from castor oil and nanostructured carbon fillers. Polymer Composites. 2017 Jul 19. E-pub ahead of print.

7. Nasouri K, Shoushtari AM. Designing, modeling and manufacturing of lightweight carbon nanotubes/polymer composite nanofibers for electromagnetic interference shielding application. Composites Science and Technology. 2017;145:46-54.

8. Pojanavaraphan T, Magaraphan R. Fabrication and characterization of new semiconducting nanomaterials composed of natural layered silicates (Na+- MMT), natural rubber (NR), and polypyrrole (PPy). Polymer. 2010;51(5):1111-1123.

9. Thostenson ET, Li C, Chou TW. Nanocomposites in context. Composites Science and Technology. 2005;65(3-4):491-516.

10. Ramoa SDAS, Barra GMO, Merlini C, Livi S, Soares BG, Pegoretti A. Novel electrically conductive polyurethane/ montmorillonite-polypyrrole nanocomposites. Express Polymer Letters. 2015;9(10):945-958.

11. Ramôa SDAS, Barra GMO, Merlini C, Schreiner WH, Livi S, Soares BG. Production of montmorillonite/polypyrrole nanocomposites through in situ oxidative polymerization of pyrrole: Effect of anionic and cationic surfactants on structure and properties. Applied Clay Science. 2015;104:160-167.

12. Shakoor A, Rizvi TZ, Hina M. Charge transport mechanism in intercalated polypyrrole aluminum-pillared montmorillonite clay nanocomposites. Journal of Applied Polymer Science. 2012;124(4):3434-3439.

13. Merlini C, Barra GMO, Cunha MDPP, Ramôa SDAS, Soares BG, Pegoretti A. Electrically conductive composites of polyurethane derived from castor oil with polypyrrole-coated peach palm fibers. Polymer Composites. 2017;38(10):21462155 .

14. Merlini C, Barra GMO, Schmitz DP, Ramôa SDAS, Silveira A, Araujo TM, et al. Polyaniline-coated coconut fibers: Structure, properties and their use as conductive additives in matrix of polyurethane derived from castor oil. Polymer Testing. 2014;38:18-25.

15. Merlini C, Soldi V, Barra GMO. Influence of fiber surface treatment and length on physico-chemical properties of short random banana fiber-reinforced castor oil polyurethane composites. Polymer Testing. 2011;30(8):833-840.

16. Lopes RVV, Zamian JR, Resck IS, Sales MJA, Santos ML, Cunha FR. Physicochemical and rheological properties of passion fruit oil and its polyol. European Journal of Lipid Science and Technology. 2010;112(11):1253-1262.

17. Kassim A, Mahmud HNME, Adzmi F. Polypyrrolemontmorillonite clay composites: An organic semiconductor. Material Science Semiconductor Processing. 2007;10(6):246251. 
18. Boukerma K, Piquemal JY, Chehimi MM, Mravcáková M, Omastová M, Beaunier P. Synthesis and interfacial properties of montmorillonite/polypyrrole nanocomposites. Polymer. 2006;47(2):569-576.

19. Gao JW, Li G, Yao YF, Jiang JM. Preparation and Characterization of Montmorillonite/Polypyrrole Nanocomposites by In-Situ Chemical Polymerization. Journal of Macromolecular Science, Part B: Physics. 2011;50(7):1364-1375.

20. Ramoa SDAS, Barra GMO, Merlini C, Livi S, Soares BG, Pegoretti A. Electromagnetic interference shielding effectiveness and microwave absorption properties of thermoplastic polyurethane/ montmorillonite-polypyrrole nanocomposites. Polymer Advanced Technologies. 2018;29(5):1377-1384.
21. Moucka R, Mravcáková M, Vilcáková J, Omastová M, Sáha P. Electromagnetic absorption efficiency of polypropylene/ montmorillonite/polypyrrole nanocomposites. Materials \& Design. 2011;32(4):2006-2011.

22. Kirkpatrick S. Percolation and Conduction. Reviews of Modern Physics. 1973;45(4):574-588.

23. Ray SS, Okamoto M. Polymer/layered silicate nanocomposites: a review from preparation to processing. Progress in Polymer Science. 2003;28(11):1539-1641.

24. Magioli M, Soares BG, Sirqueira AS, Rahaman M, Khastgir D. EMI shielding effectiveness and dielectrical properties of SBS/PAni.DBSA blends: Effect of blend preparation. Journal of Applied Polymer Science. 2012;125(2):1476-1485. 